\title{
DAR PALABRA A LOS FANTASMAS: LA FIGURA DEL EMIGRANTE EN LA OBRA DE THEO ANGELOPOULOS
}

\author{
Aarón Rodríguez Serrano \\ Universidad Europea de Madrid
}

\begin{abstract}
"El decorado es un monumento. El monumento representa, cien veces ampliado, a un hombre que hizo historia. Una esperanza petrificada. Su nombre es intercambiable. La esperanza no se cumplió (...) La piedra está habitada. En los amplios agujeros de la nariz y los ojos, en los pliegues de la piel y del uniforme del monumento derribado, reside el sector indigente de la población de la metrópolis" (Heiner Müller, Máquina Hamlet)
\end{abstract}

\section{INTRODUCCIÓN: LA MIRADA DEL AUTOR}

Uno de los peligros que puede encerrar el estudio de un autor como Angelopoulos es, sin duda, la fascinación que provoca automáticamente su personal manera de entender el ejercicio de la puesta en escena. No resulta extraño que muchas de las críticas dirigidas hacia este singular director le acusen precisamente de formalista, de pomposo y alambicado generador de discursos huecos ${ }^{1}$. Y es que la escritura de Angelopoulos tiene como uno de sus rasgos principales la capacidad de no dejar indiferente a nadie: atrapa o aburre, inquieta o molesta, pero siempre parece desafiar al espectador en lo que, sin duda, es uno de los trazos más auténticos e individuales del cine europeo de las últimas décadas.

Sin embargo, nuestro estudio no pretende focalizar su atención en ese interesante laberinto formal, sino reivindicar ciertos valores del cine de Angelopoulos que quizá hayan sido eclipsados en algún momento por el propio poder de las imágenes que los arropan. Acusar al director de formalista es negar al mismo tiempo la validez de su palabra pronunciada, olvidar voluntariamente que en su filmografía hay un núcleo irreductible de compasión, de diálogo

1 Cada estreno del director griego suele venir acompañados de alguna crítica más o menos mordaz en la prensa nacional. Baste como ejemplo reseñar que el único trabajo más o menos extenso que se ha publicado hasta el momento sobre el estreno de The dust of time (I skoni tou hronou, 2008) fuera de nuestras fronteras haya sido Boyero, 2009. 
nada paternalista con el otro, el inmigrante, el sujeto condenado a vagar por tierras que no son la suya.

Desde sus primeros títulos, el director griego ha sido capaz de ofrecer uno de los ejercicios de funambulismo más clarificadores en el contexto de los cines de la modernidad (Font, 2002, 321-322). Ya sabemos que uno de los grandes problemas planteados por la crítica de corte marxista durante los años sesenta y setenta -una crítica que no dudó en dilapidar a autores como Bergman o Antonioni acusándoles de egocéntricos, narcisistas y otros calificativos despreciativos- era precisamente cómo se podía conciliar el universo personal de los llamados "autores" con la brutal emergencia de los problemas sociales de la época. Y, ciertamente, quizá sea necesario empezar diciendo que las cintas de Angelopoulos son profundamente inútiles como herramientas de una lucha de clases de salón: la afilada exigencia en términos de puesta en escena de la que hablábamos antes las hace irremediablemente crípticas para un público no iniciado, por no hablar de la tonelada de referencias mitológicas, literarias o filosóficas que componen el entramado textual de cada uno de los títulos. Por el contrario, cuando somos atrapados en el interior de su filmografía, no es muy difícil intuir que toda la obra de Angelopoulos es una de las síntesis más perfectas entre la voluntad autoral y el encuentro con la problemática social. La suya es una búsqueda política y poética en la que conviven en perfecta armonía elementos biográficos, salvajes críticas contra la derecha y la izquierda, latidos de la herencia cultural europea, y sobre todo, un compromiso con la actualidad que difícilmente puede rastrearse en otros directores. Al fin, sólo podemos señalar que hemos decidido decantarnos por Angelopoulos como objeto último de nuestro estudio por el lugar principal que otorga al emigrante como centro de esa dialéctica poética y social.

\section{MITOS Y HOMBRES SIN TIERRA}

Sobre un paisaje difícilmente habitable, en un contrastado y violento blanco y negro, un hombre camina lentamente arrastrando una maleta. Parecería que lleva sobre sus hombros un dolor insoportable, un dolor que podría ser el de la historia misma. La filmografía de Angelopoulos comienza con esas imágenes seminales, con el retorno de un emigrante a su hogar tras varios años de ausencia. Se trata de Reconstrucción (Anaparastasi, 1970), una amarga crónica poliédrica y brecthiana sobre el asesinato de ese humilde emigrante recién llegado de Alemania a manos de su mujer y su amante.

La película puede ser leída en primer lugar como si de una moderna versión de la Orestiada se tratase. Como en casi todo el cine de Angelopoulos, cada secuencia, cada personaje, parece esconder en su interior una referencia más o menos explícita a la literatura griega. Sin embargo, un análisis textual de los detalles nos demostraría hasta qué punto Angelopoulos se esfuerza por reactualizar el mito, por no permitir que la catástrofe contemporánea del emigrante se convierta en una pedante nota a pie de página, en un polvoriento guiño referencial. Por ejemplo, podemos destacar rasgos como el siguiente: «En la banda sonora se escucha una vieja canción popular en la voz de un hombre que canta en un tono elevado, al estilo del Epiro, la parte norte de Grecia que linda con Albania» (Horton, 2001, 85).

En la muy compleja radiografía que Angelopoulos parece proponer sobre la Europa de la segunda mitad del siglo XX, las referencias entre esos tres ejes geográficos (Grecia-AlbaniaAlemania) son los ecos de un terror que no cesa, de una imposible injusticia geográfica en la que miles de seres humanos son obligados a desplazarse sin rumbo, sin final, en un violento 
ciclo en el que las vidas se compran o se pierden. Así, los niños de Paisaje en la niebla (Topio stin omichli, 1988) se dirigen hacia una Alemania que no existe más que en su imaginación en busca de un padre perdido. Al otro lado del espejo, unos años después, un niño albanés llega a Grecia en busca de refugio en la absolutamente conmovedora La eternidad y un día, de la que nos ocuparemos en el epígrafe final de nuestro artículo. Nos encontramos, sin duda, con una problemática política que quizá no haya sido tratada como debiera en el cine europeo.

Ese primer hombre que regresa a su hogar en Reconstrucción, manchándose del lodo de un camino que difícilmente puede ya reconocer como suyo, guarda en su interior la inmensa catástrofe que late en el viejo continente y que años después eclosionará frente al objetivo del director en el conflicto de los Balcanes. Por un lado, la supuesta sociedad del bienestar que abandona -Alemania- nada quiere saber ya de él, ni de los que como él, acudieron a buscar trabajo y seguridad en sus infraestructuras. Como tantos otros ciudadanos griegos y españoles de la época, ha ofrecido su esfuerzo a cambio del espejismo del capital, arriesgándose a perder su identidad en un marasmo de promesas puramente imaginarias. Por otro lado, el suyo es un rol a medio camino entre el chivo expiatorio y el triste bufón que regresa al hogar únicamente para ser asesinado. De hecho -y esta es una de las críticas mayores que se le pueden hacer a la cinta- el relato nada parece querer saber ni de la experiencia del exilio, ni de la identidad concreta de ese personaje cuya única función es, queda dicho, morir. Este rasgo será fundamental posteriormente cuando analicemos la evolución de la obra del director desde el nosotros marxista hasta el yo del emigrante.

\section{PADRES/EMIGRANTES}

Esta deuda, que quizá pueda achacarse a la falta de experiencia del director en aquel momento, o quizá simplemente sitúe en el interior del emigrante una de las fronteras mismas que el relato no debe traspasar, planeará desde entonces en el resto de su filmografía. De hecho, nos atreveríamos a señalar que sólo queda resuelta en la mayúscula Viaje a Citera (Taxidi sta Kythira, 1984), cuando la madurez temática y formal de Angelopoulos ya está fuera de toda duda. De nuevo, un hombre que regresa a su hogar. Y de nuevo, una serie de humiIlaciones que esperan a esa suerte de Ulises triste y contemporáneo.

Como en tantas otras películas del director, Viaje a Citera fantasea sobre la deuda contraída por el padre emigrante. Padre, como el de Reconstrucción o el de Paisaje en la niebla, que se marchó al extranjero, en este caso por un compromiso político. Sin embargo, podemos llegar todavía más lejos al intentar despejar esa figura ausente en la ecuación simbólica del cine del director:

El propio vacío muestra entonces su cara. No hay más remedio que afrontarlo. Encontrar un modo de decir yo. Y para decir yo no está de más apelar al padre. Naturalmente, no un operador biológico, sino a un normalizador simbólico. Dicho con otras palabras: apelar a la función constituyente de la propia subjetividad. Ninguna otra cosa, sin duda, la determina más. Ya es importante. Sin esa estructura identificatoria, acaso el sujeto se abismará en el desvarío (Vidal Estévez, 2009, 41-2).

La conexión entre el padre -simbólico- ausente y la tragedia del emigrante no tiene nada de gratuita. La deuda funciona en dos direcciones: por un lado, la mirada de unos hijos 
abandonados que entienden el dolor de la ausencia como una herida no justificable por los espejismos de la sociedad del bienestar o de la bandera ideológica de turno. Por otro lado, el brutal fracaso de las políticas de esos países, que no han sabido ofrecer unas condiciones mínimas de existencia digna a sus habitantes. Sin embargo, como decíamos al principio, la mirada sobre la inmigración no pasa aquí por una bobalicona y forzada postura paternalista. Antes bien, lo que está en juego es la responsabilidad de cada uno, la manera en la que los sujetos se resisten precisamente a ser domesticados por las ideologías, aunque acabe por costarles la propia vida. Spyros, el anciano que retorna a su casa después de treinta años de exilio al otro lado del telón de acero en Viaje a Citera, acude con la desolación, con la desesperación de las promesas rotas, sin ni siquiera una palabra esperanzadora que donar a esos hijos que tanto le han esperado. Su hija Voula es precisamente la primera en advertir hasta qué punto su exilio ha resultado inútil y doloroso: le acusa de egoísta, de haber puesto sobre todas las cosas un espejismo político, de haber(se) sometido a la vida del exiliado en el nombre de uno de los fracasos más mayúsculos del siglo XX. Cuando años después, en La mirada de Ulises (To vlema tou Odyssea, 1995), tengamos la ocasión de ver a Harvey Keitel descendiendo un río junto a una enorme estatua de Lenin despiezada, comprenderemos hasta qué punto Angelopoulos fue capaz de intuir las nutricias conexiones entre la figura del padre ausente y las consecuencias de la emigración política en Europa. El fracaso del padre emigrante que nos ocupa es, ante todo, un fracaso que pertenece al orden mismo de lo simbólico. Sus confesiones, los relatos de su lucha, la manera en la que intenta compaginar mentalmente su experiencia en el exilio con su juventud en Grecia, están impregnadas de un desgarrador patetismo, de ese imposible esfuerzo por justificar(se en) la imposibilidad de sustentar su palabra, labor que el propio Angelopoulos parece atribuírse.

De hecho, el último plano de la cinta no podría ser más elocuente: condenado a permanecer en mitad de ningún lugar, el anciano y su esposa vagan a la deriva sobre una frágil plataforma de madera. El inmigrante se convierte en náufrago, el exiliado se convierte en un error histórico del que absolutamente nadie quiere hacerse cargo. Su presencia deriva en un serio problema para el presente, para la vida de sus hijos, pero también para esa historia que las sociedades del bienestar se empeñan en escribir a toda velocidad al margen del sabor de la experiencia de los sujetos que las conforman. Su balsa, tan frágil y al mismo tiempo tan elocuente, acaba por convertirse en la única nacionalidad del exiliado: una tierra inestable, efímera, que acabará por arrojarle a él y a su esposa a una muerte segura. Angelopoulos, de una manera mucho más poética y dolorosa, decide cerrar su relato con esas dos sombras que se pierden en un horizonte imposible.

¿Dónde nos deja, por lo tanto, esta visión del inmigrante propuesta por el director griego? Podríamos pensar que en uno de los territorios más inquietantes que el psicoanálisis nos ha legado en su estudio de la historia:

Hay que distinguir entre la historia simbólica (el conjunto de narraciones míticas explícitas y las prescripciones ético-ideológicas que constituyen la tradición de una comunidad, es decir, lo que Hegel hubiera denominado su "sustancia ética") y su Otro obsceno, la incognoscible historia fantasmática, espectral, que sirve de sostén efectivo a la tradición simbólica explícita (...) uno se convierte en miembro a pleno título de una comunidad no simplemente al identificarse con su tradición simbólica explícita, sino al asumir la dimensión espectral que sirve de sostén a esta tradición: 
los espectros imperecederos que acosan a los vivos, la historia secreta de las fantasías traumáticas trasmitidas " entre líneas", a través de sus faltas y distorsiones (Zizek, 2002, 86-7).

Ciertamente, el emigrante al final de Viaje a Citera, acaba haciendo suya esta incómoda presencia del fantasma.

\section{FANTASMAS/EMIGRANTES}

Una de las grandes intuiciones del cine del director es, sin duda, la manera en la que convierte la figura del emigrante en una de las pruebas evidentes del fracaso mismo de las sociedades del bienestar. La manera en la que se hacinan los cuerpos y las almas de los desterrados en El paso suspendido de la cigüeña (To metero vima tou pelargou, 1991) o el modo en el que los niños albaneses son convertidos en moneda de cambio de las mafias en La eternidad y un día son algunos de los retratos cinematográficos más descarnados, y a mismo tiempo más honestos, sobre la propia construcción fantasmática del emigrante.

Si nos tomamos algo de tiempo para reflexionar sobre esta última cinta -no en vano, resultó ganadora de la Palma de Oro del Festival de Cannes de 1998-, veremos cómo la construcción fantasmal del emigrante se plantea con una crudeza radical, en oposición incluso a muchos de los hábitos "exquisitos" de la intelectualidad europea. ¿De qué habla exactamente La eternidad y un día? Sin duda que se trata de una película crepuscular, impregnada desde el primer fotograma hasta el último por la presencia de la muerte. Durante sus últimas horas de vida, Alexandros (Bruno Ganz), un famoso escritor gravemente enfermo, entabla una sincera amistad con un niño albanés sin nombre (Achileas Skevis) al que salva de ser detenido por la policía. Con semejante punto de partida, cualquier otro director habría acabado hilando una fábula llena de buenas intenciones, estupenda a la hora de limpiar las conciencias de los espectadores más complacientes, agridulce pero finalmente comprensiva en su enfoque del problema. Nada de eso hay en la cinta del director, que no duda en hacer chocar el egoísmo de una cierta clase educada y aparentemente moderna -representada con sorprendente precisión en la hija de Alexandros (Eleni Gerasimidou) que se niega a cuidar del perro de su padre moribundo- con el verdadero horror de los países más deshilvanados de Europa. Utilizando una vez más la frontera como preciso operador textual, Angelopoulos decora de niebla y cadáveres la línea que separa Grecia con Albania, genera una escalofriante escenografía en la que una legión de muertos vivientes intenta desesperadamente entrar en el país desarrollado para someterse a un nuevo ciclo de vejaciones, hambre y miedo. Como muy bien señala Gómez Tarín en su excelente análisis de la cinta:

El niño de origen albanés supone la irrupción de lo real -del saber- en la inscripción del protagonista en la sociedad, al borde de la muerte anunciada; de su mano, Alexander iniciará un viaje a los infiernos del mundo actual, que veía de tan lejos (...) A través del niño, Angelopoulos interpelará a su personaje y al espectador (ritual de la incineración en que se multiplican las miradas a cámara), pero también lo hará desde la mirada de Alexander (Gómez Tarín, 2000, 67). 
Resulta asombrosa, siguiendo la teoría sobre el fondo fantasmático de las sociedades propuesta por Zizek, la manera en la que Angelopoulos construye una suerte de "enunciación doble" en la que es factible encontrar, por ejemplo, la reconstrucción de la vida de un poeta griego exiliado en el siglo XIX -Dionisios Solomós- con la implacable presencia de lo real encerrada en el cuerpo destrozado de Salim, uno de los niños inmigrantes. Parecería por momentos que, de una manera desesperada, el director necesita conciliar a toda costa esa ingente cantidad de referencias culturales tan preciadas por la modernidad fílmica europea con la emergencia misma de lo que sucede en las calles. Y, ciertamente lo logra, en la fabulosa secuencia en la que los niños entonan una hipnótica y desesperada oración por su compañero muerto:

¡Selim! ¡Qué pena que no vengas con nosotros! ¡Selim, tengo miedo! ¡Selim, el mar es muy grande! ¿Qué te espera dónde vas? ¿Qué nos espera donde vamos? Hubo montes, barrancos, policías. Pero no volvimos atrás. Ahora veo el mar sin fin. Por la noche vi a mi madre, en la puerta, triste. Era Navidad. Llevaban las montañas y sonaban las campanas. Si estuvieras aquí para hablarnos de los puertos de MarseIla, de Nápoles. De ese gran mundo. ¡Selim, háblanos de su mundo grande! ¡Selim, háblanos, Selim, Selim! ${ }^{2}$

Ciertamente, que la intervención de los niños no podría leerse desde los cánones del realismo más rancio. Sin embargo, el latido poético, el esfuerzo que el director realiza para dotar de dignidad y belleza las palabras de los fantasmas de las sociedades del bienestar es, cuanto menos, conmovedor. Los niños, en el filo inicial de su catástrofe misma, coleccionan palabras preñadas de una inmensa nostalgia: un mar sin fin, un camino sin fin, historias de madres tristes y de mundos imaginados, fragmentos robados de un sueño emigrante europeo que quizá solamente ha sido plasmado con tanta belleza y tanto dolor en otra cinta: El tiempo de los gitanos (Dom za vesanje, Emir Kusturica, 1988).

Después de todo, el problema central al que Angelopoulos intenta enfrentarse es la manera en la que ese anciano griego a punto de morir y ese niño ya experto de la muerte en vida, pueden encontrar un lenguaje común, un vocabulario que no hiera ni sus historias ni sus pasados, y que no acabe tomando parte de la manida dialéctica entre el amo y el esclavo. Esos dos cuerpos que el azar junta en una bulliciosa calle de Tesalónica, descubren de pronto la subjetividad del otro, el dolor del otro. Y, a su vez, son capaces de ser reconocidos en el ansia absoluta de escapar de la propia identidad fantasmal. Salim, el niño muerto, encuentra en el desgarrador rito improvisado por sus compañeros la única posibilidad de escapar de su condición de fantasma: se convierte en leyenda, en poesía, en una presencia capaz de hablar de su "mundo grande". Recuerda conmovedoramente esa otra escena de Viaje a Citera en la que el viejo Spyros retorna a su pueblo natal para bailar un Pontiko -una especie de celebración del recuerdo mediante la danza que se repite una y otra vez en el cine del director- sobre la tumba del mejor amigo de su juventud. El ángel de Walter Benjamín continúa su vuelo desesperado, pero los hombres de Angelopoulos no se resisten a la dulce tentación del olvido, sino que se manifiestan en la muerte, en la frontera, en ese "no tener hogar" que acaba siendo cenital en la propia construcción de la tradición griega.

2 Monólogo extraído de la traducción distribuida por Intermedio en el dvd español. 


\section{CONCLUSIONES: LA APLICACIÓN DE LA FIGURA DEL EMIGRANTE A UNA POSIBLE CRONOLOGÍA DE LA OBRA DE THEO ANGELOPOULOS}

En otro lugar (Rodríguez Serrano, 2009/a y 2009/b) ya hemos hablado de cómo el cine del director comienza proponiendo una "primera etapa marxista" para después acabar en una fascinante exploración hacia el yo, hacia el dolor del propio sujeto. La construcción de personajes emigrantes sigue también esa misma lógica, desde el primer retrato apenas esbozado en Reconstrucción del que ya hemos hablado hasta la inmensa complejidad del niño protagonista de La eternidad y un día o, por supuesto, la tragedia personal del director de cine interpretado por Harvey Keitel en La mirada de Ulises.

Creemos que merece la pena detenerse en esta idea para desarrollarla con calma. Que el cine de Angelopoulos comienza con una clara voluntad política de izquierdas es algo innegable. En cierto sentido, la compañía de actores que protagoniza El viaje de los comediantes ( $O$ thiasos, 1975) puede ser leída como una colección de nómadas que vagan sin hogar por el tiempo y el espacio, en clara consonancia con las figuras emigrantes posteriores. Sin embargo, en una voluntad que todavía está demasiado localizada en la idea de realizar "obras de tesis" de marcado compromiso marxista, acaba por generar personajes fríos, distanciados, arquetipos de tragedias reactualizados que bloquean cualquier simpatía simpática, convirtiéndose así en dibujos bufonescos, patéticos, incompletos. Sin embargo, después de una cinta tan compleja y decisoria como Alejandro Magno (O Megalexandros, 1980), el cine del director parece haber llegado a un callejón sin salida. Y serán, precisamente, un puñado de emigrantes los que ejemplifiquen como nadie hasta qué punto las buenas intenciones del director comienzan a ponerse en duda. Nos referimos, por supuesto, a esos italianos perdidos que desembocan en la aldea griega con la utópica intención de predicar el anarquismo y participar en la puesta en marcha de una auténtica sociedad socialista. Angelopoulos, sin embargo, ya está arrinconado en los rincones más problemáticos de su propia ideología, y decide dar muerte a esos emigrantes a manos de un tirano en el que reverbera la locura estalinista.

La etapa posterior -la llamada Trilogía del silencio- deslumbra precisamente por la capacidad de generar personajes conmovedores, tridimensionales, de una complejidad arrolladora y de una humanidad más allá de toda duda. La figura del emigrante ya no es simplemente un colectivo -aunque volverá a esa forma en El paso suspendido de la cigüeña-, sino que se compone de auténticos sujetos individuales, reconocibles por sus heridas y sus almas desgarradas. Por supuesto que tanto en Spyros como en Alexander o en Voula -los hermanos protagonistas de Paisaje en la niebla- todavía resuenan los ecos de una marcada voluntad de cambio social, así como una pátina de inmortalidad heredada de sus referentes trágicos literarios. Sin embargo, nos encontramos ahora en un universo fílmico en el que resulta del todo imposible escapar de la subjetividad del otro, encerrarle en una bandera o bajo un mantra político. Los problematizan en la búsqueda de sus paraísos perdidos, en el dolor de su regreso al hogar, en su propia naturaleza de sujetos heridos de exilio.

El futuro del director sigue siendo, por el momento, un interrogante. A la espera de que finalmente se distribuya en nuestro país Las cenizas del tiempo, sólo podemos juzgar su última trilogía gracias a su primera parte, Eleni (Trilogia: To livadi pou dakryzei, 2004). Sin embargo, el fabuloso plano inicial que abre esta película parece comprimir con precisión 
todo lo que aquí hemos expuesto ${ }^{3}$. Surgidos de la nada, una legión de hombres, mujeres y niños impolutamente vestidos atraviesan un territorio enfangado. Un narrador, mediante la voz fuera de campo, nos informa de que esos hombres son emigrantes que han sido expulsados por los bolcheviques de sus ciudades, expatriados, nuevos emigrantes. La cámara, en esa habitual facilidad para la construcción de planos secuencia típicos del director, se acerca hacia ellos hasta reencuadrar únicamente a la familia que encabeza la marcha. El padre se dirige directamente al público, intenta explicar, intenta dar los motivos y ofrecer las coordenadas históricas de su exilio. Sin embargo, una vez más, la atención acaba localizada en los sujetos individuales, en los niños, en su promesa de futuro ya truncada. El encuadre parece zambullirse en uno de sus charcos que el propio director denomina "la tierra que llora", los rostros de los emigrantes se difuminan, se pierden, se confunden en el movimiento de las aguas. Contra todo pronóstico, alguien le pregunta a una de las niñas por su nombre. Su voz, inundada por el miedo, musita simplemente: Eleni.

De igual manera que en la escena ya comentada de La eternidad y un día, ahora Angelopoulos vuelve a investir simbólicamente al emigrante. Salim se convierte en oración y poesía. Eleni coloca su nombre sobre el relato mismo, se funde en él, comienza su propia historia haciendo que su voz sea la más humana, la más hermosa, la única que realmente se atreve a tocar en el interior del espectador. Ésa es, sin duda, una de las grandes lecciones que podemos aprender de la filmografía del director griego: la absoluta importancia de escuchar, en igualdad de condiciones, las voces de los fantasmas de la historia.

\section{BIBLIOGRAFÍA}

BOYERO, Carlos (2009), "Festival de Berlín", El País (13-II-2009).

FONT, Doménech (2002), Paisajes de la modernidad. Cine europeo, 1960-1980, Barcelona, Paidós.

GÓMEZ TARÍN, Francisco J. (2000), "La eternidad y un día: Recuperación de la memoria", El Viejo Topo, $n^{\circ} 140$.

HORTON, Andrew (2001), El cine de Theo Angelopoulos: Imagen y contemplación, Madrid, Akal.

RODRÍGUEZ SERRANO, Aarón (2009a), “Exiliados del tiempo: Representaciones masculinas en el cine de Theo Angelopoulos", Shangri-la, n 8, pp. 132-144.

- (2009b), "Los hijos del azar: la problemática del sujeto frente a la historia en el cine de Theo Angelopoulos", El Genio Maligno, n 4, pp. 103-120.

VIDAL ESTÉVEZ, Manuel (2009), Poemas de la desolación: El cine de Theo Angelopoulos, Huesca, Festival Cine de Huesca.

ZIZEK, Slavoj (2002), El frágil absoluto o ¿Por qué merece la pena luchar por el legado cristiano?, Valencia, Pre-Textos.

ZOLLER SEITZ, Matt, Contemplative Cinema Blog-a-Thon: Theo Angelopoulos'The weeping meadow, en http://www.slantmagazine.com/house/2007/01/contemplative-cinemablog-a-thon-theo-angelopoulos-the-weeping-meadow/

3 Para un desarrollo más ampliado de la lectura microanalítica de esta escena nos gustaría remitirnos a Zoller Seitz, 2007.

Quaderns, 6 (2011), pp. 95-102 